\title{
Effectiveness of different retreatment techniques in the removal of gutta-percha cones and bioceramic-based root canal sealer in the different parts of the root canal
}

\section{Mirela Marinova-Takorova ${ }^{1}$, Elka Radeva ${ }^{1}$, Iva Kisjova ${ }^{2}$, Emilia Naseva $^{3}$}

1. Department of Conservative Dentistry - Faculty of Dental Medicine - Medical University - Sofia, Bulgaria;

2. Department of Imaging Diagnostics - Military Medical Academy - Sofia, Bulgaria;

3. Department of Health Economics - Faculty of Public Health - Medical University - Sofia, Bulgaria;

\begin{abstract}
The aim of the presented study was to compare the efficacy of three different retreatment techniques in the removal of gutta-percha and bioceramic-based sealer in the different parts of the root canal. Extracted human single rooted teeth $(n=66)$ were used. Teeth were divided into six groups: Gr1 retreated using ProTaper Universal Retreatment files after filling with central cone technique; Gr2 ProTaper Universal Retreatment files after cold lateral compaction technique; Gr3 - hand instruments
\end{abstract}


after central cone filling technique; Gr4 - hand instruments after cold lateral compaction technique; Gr5 - ultrasonic tips after central cone technique; Gr6 - ultrasonic tips after cold lateral condensation. Residual filling material was evaluated using computed tomography and microscope observation. Best removal of filling material was achieved in the middle part or the root canal and worse in the coronal. When central cone technique was used, best cleaning was observed with hand instruments in the coronal and middle part and with ultrasound in the apical part. There was no statistically significant difference in the coronal and middle third of the canal when lateral compaction technique was used, the ultrasound performed best in the apical part.

Keywords: retreatment, bioceramic-based sealer, machine retreatment files.

\section{Introduction}

Despite of the high success rates of endodontic treatment there are still cases, when failures occur. The present data in literature reveals overall success rates varying between 78 and $90 \%[1,2,3]$. The main reasons for endodontic failures are persistence of bacteria, inadequate filling of the canal (insufficiently or overfilled), coronal leakage, untreated root canals, iatrogenic errors [4]. The most common mean of treatment is nonsurgical retreatment, especially in cases with technical deficiencies. It is reported to have higher success rates (78\%) than surgical retrograde one (63\%) [1]. The success of the nonsurgical retreatment depends on the complete removal of the root filling material and the consequent adequate cleaning and shaping of the entire root canal system.

Usually the root canal is filled with gutta-percha and a sealer [5]. Sealer is needed, because of the lack of bonding of the gutta-percha to the dentine of the root canal [6]. Sealers are divided into several groups, according to their chemical composition: zinc oxide-eugenol, calcium hydroxide, glass-ionomer, resin [7]. Recently sealers with calcium-silicate based technology have been developed. They have two very important advantages. They are biocompatible and they contain calcium phosphate, which has a chemical composition and crystalline structure similar to tooth apatite, which results in good bonding to root dentin $[8,9,10]$. On the other side the good boding of these materials leads to one of their disadvantages - they are difficult to be removed from the root canal system if retreatment is needed $[11,12]$. The present data concerning the retreatability of those sealers is controversial $[12,13]$.

Removal of the root canal filling can be achieved with several different methods- ultrasonic technique, hand instruments, chemical solvents, heat pluggers, rotary nickel-titanium instruments, specifically designed for removal of root canal filling material $[11,13,14]$. The efficacy of these methods can be assessed by many ways. Some of the methods include splitting of the teeth and observation under microscope, others - making the tooth transparent $[15,16]$. These techniques need the specimens to be destroyed. Other methods are radiographic examination and computed tomography $[16,17]$. The aim of the presented study was to compare the efficacy of three different retreatment techniques in the removal of gutta-percha and bioceramic-based sealer in the different parts of the root canal. 


\section{Materials and methods}

Extracted human single rooted teeth $(n=66)$ with straight roots and completely formed apices were collected, cleaned and stored in $0.5 \% \mathrm{NaOCl}$. They were examined with an operating microscope (Leica M320, Germany) under x16 for the presence of micro cracks. The crowns were removed with a diamond disk and $15 \mathrm{~mm}$ root segments were obtained. Roots with size of the apical foramen above 20 were excluded. A K-file size 15 was used to determine working length (one $\mathrm{mm}$ shorter than the length till the apical foramen).

Roots were enlarged using torque-controlled electric motor, operated according to the manufacturer's instructions with ProTaper Universal files (Dentsply Maillefer, Bellaigues, Switzerlandup to size $\mathrm{F} 2$. $\mathrm{NaOCl}$ $5.25 \%$ was used for irrigation during root canals enlargement. The roots were dried with paper points (Dentsply Maillefer, Bellaigues, Switzerland). Half of the canals $(n=33)$ were filled with matched-taper single cone technique and bioceramic based sealer (MTA Fillapex, Angelus, Londrine, PR, Brazil) and the rest $(n=33)$ with cold lateral compaction technique (master cone\#25) and the same sealer. The coronal access cavities of the specimens were sealed with temporary filling material (MD-Temp, Meta Biomed Co Ltd, South Korea). Postoperative radiographs were made in order to check the quality of the fillings. Teeth were stored in $100 \%$ humidity for 3 weeks to allow complete setting of the sealer.

Teeth were randomly assigned into six groups $(n=11)$, according to the retreatment method and filling technique: Gr1 - retreated using ProTaper Universal Retreatment files and filled with central cone technique; Gr2 - retreated using ProTaper Universal Retreatment files and filled with cold lateral compaction technique; Gr3 - hand instruments and central cone filling technique; Gr4 - hand instruments and cold lateral compaction technique; Gr5 - ultrasonic tips and central cone technique; Gr6 - ultrasonic tips and cold lateral condensation.

For all groups first Gates Glidden \#3 (Dentsply Maillefer, Bellaigues, Switzerland) was used to remove the gutta-percha in the coronal $2 \mathrm{~mm}$. Then solvent (orange oil) was applied.

For groups one and two ProTaper Universal Retreatment files were used consequently - D1, D2, D3 - in a crown down manner to remove the gutta-percha from the coronal middle and apical part of the root canal. The patency of the canal was checked with a $\mathrm{K}$ file \#25 (Dentsply Maillefer, Bellaigues, Switzerland). For groups three and four the retreatment was preceded with $\mathrm{H}$ - files (Dentsply Maillefer, Bellaigues, Switzerland) with clock wise half-turn and brushing motions until root canal patency was reestablished. Ultrasonic tips (EMS) \# 20 were used for the retreatment of the third group.

Working length and smoothness of all root canals was checked at the end with a $\mathrm{K}$ file \#25. Retreatment was accepted as fulfilled when the last instrument that went to full working length was with no filling material on it and the walls were felt smooth. Three millilitres of $5.25 \%$ NaOCL were used for irrigation during the removal of the filling material and two millilitres for a final flush. The canals were dried with paper points.

Specimens were numbered and scanned with CT. The volume of sealer in each third was determined according to the following grading system: score 0 - no presence of residual filling material; score 1 - less than $1 / 3$ of the wall is covered with residual filling material; score $2-1 / 3$ to $2 / 3$ of the wall is covered with 
filling material; score 3 - more than $2 / 3$ is covered; score 4 - the whole wall is covered wit residual filling material.

Teeth were sectioned longitudinally and observed under microscope (Leica M320, Germany) under 16x magnification. Images were taken and the amount of residual material in the different portions (apical, coronal, middle) of the canal was evaluated according to the above mentioned scale.

SPSS software (Version 19) was used to analyze the data. The remaining root filling material in the different parts of the root canals was analyzed using Kruskal-Wallis test for comparison of more than 2 groups and Mann-Whitney for comparison of 2 groups. Kendall's tau_b correlation coefficient was used to asses the results achieved with computed tomography and operating microscope.

\section{Results}

Complete removal of filling material was not achieved in any part of the root canal. In most of the samples the material that was found was sealer. Only in $6 \%$ of the cases was found gutta-percha in the coronal and middle part of the root canal and in $9 \%$ in the apical.

Table 1: Samples with different scores in the different regions of the root canal

\begin{tabular}{|c|c|c|c|}
\hline & & $\mathrm{n}$ & $\%$ \\
\hline M coronal & Absence of residual filling material & 48 & 36.4 \\
\hline & Residual filling material covering less than $1 / 3$ of the wall & 51 & 38.6 \\
\hline & Residual filling material covering $1 / 3$ to $2 / 3$ of the wall & 22 & 16.7 \\
\hline & Residual filling material covering more than $2 / 3$ of the wall & 10 & 7.6 \\
\hline & Whole wall covered with residual filling material & 1 & 0.8 \\
\hline $\mathrm{M}$ middle & Absence of residual filling material & 67 & 50.8 \\
\hline & Residual filling material covering less than $1 / 3$ of the wall & 49 & 37.1 \\
\hline & Residual filling material covering $1 / 3$ to $2 / 3$ of the wall & 14 & 10.6 \\
\hline & Residual filling material covering more than $2 / 3$ of the wall & 2 & 1.5 \\
\hline & Whole wall covered with residual filling material & 0 & 0.0 \\
\hline M apical & Absence of residual filling material & 57 & 43.2 \\
\hline & Residual filling material covering less than $1 / 3$ of the wall & 44 & 33.3 \\
\hline & Residual filling material covering $1 / 3$ to $2 / 3$ of the wall & 13 & 9.8 \\
\hline & Residual filling material covering more than $2 / 3$ of the wall & 17 & 12.9 \\
\hline & Whole wall covered with residual filling material & 1 & 0.8 \\
\hline
\end{tabular}


In the presented study complete removal of the filling material in the coronal part of the root was achieved in $36,4 \%$ of the samples (table 1). When comparing the different retreatment techniques least cases with complete removal of filling material were observed when NiTi rotary instruments were used (10.6\%). The results achieved with hand instruments and ultrasonic tips were comparable $(31.81 \%$ and $30.3 \%$ respectively). As a whole best removal of root canal filling in the coronal part was achieved using the ultrasonic tips and the hand instruments, the difference between the two methods being statistically insignificant (table 2; fig 1).

Table 2: Difference in the cleaning of the filling material in the different parts of the root canal with the different techniques.

\begin{tabular}{|l|l|l|l|l|}
\hline $\begin{array}{l}\text { Part of the root } \\
\text { canal }\end{array}$ & $p$ overall & $p$ machine/ hand & $\begin{array}{l}p \text { machine/ } \\
\text { ultrasonic tips }\end{array}$ & $\begin{array}{l}p \text { hand/ ultrasonic } \\
\text { tips }\end{array}$ \\
\hline Coronal & 0.001 & 0.001 & 0.002 & 0.769 \\
\hline Middle & 0.043 & 0.019 & 0.771 & 0.044 \\
\hline Apical & 0.001 & 0.008 & 0.001 & 0.272 \\
\hline
\end{tabular}

When comparing the two filling techniques complete removal was recorded in $28.78 \%$ of the samples filled with lateral compaction technique and $42.42 \%$ from the ones with central cone technique.

Concerning the middle part of the root canal, complete removal of the filling material was achieved in $50.8 \%$. The hand instruments showed best results in this part $(43.96 \%$ of the samples were absolutely clean), while the NiTi and ultrasonic instruments presented worse (27.27\% and 31.8\% respectively) (fig.2, tabl.2).

Fig. 1: Plots of the residual filling material in the coronal part

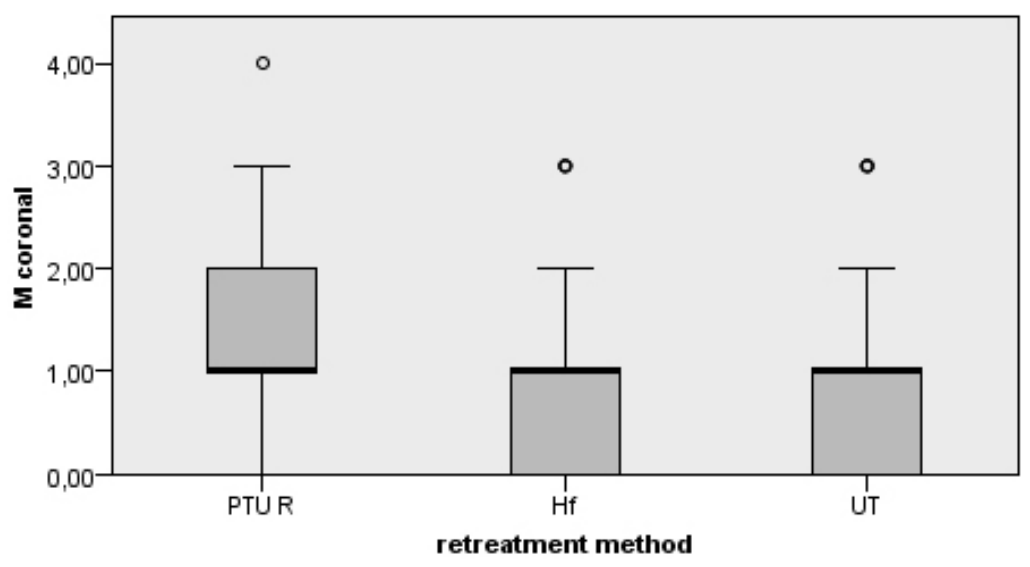


Fig. 2: Plots of the residual filling material in the middle part

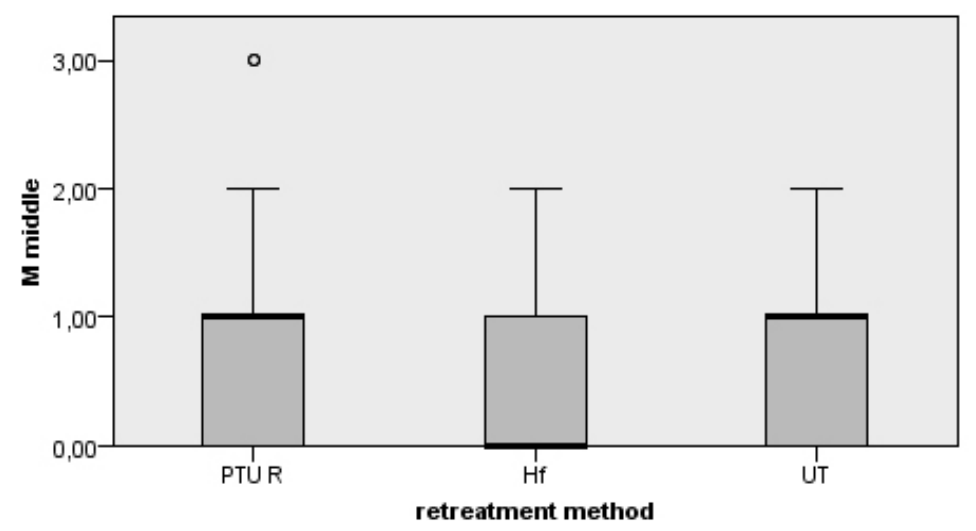

Lateral compaction filling technique again presented with less samples with complete removal of filling material (45.45\% compared with $56.06 \%$ for the single cone technique).

Fig. 3: Plots of the residual filling material in the apical part

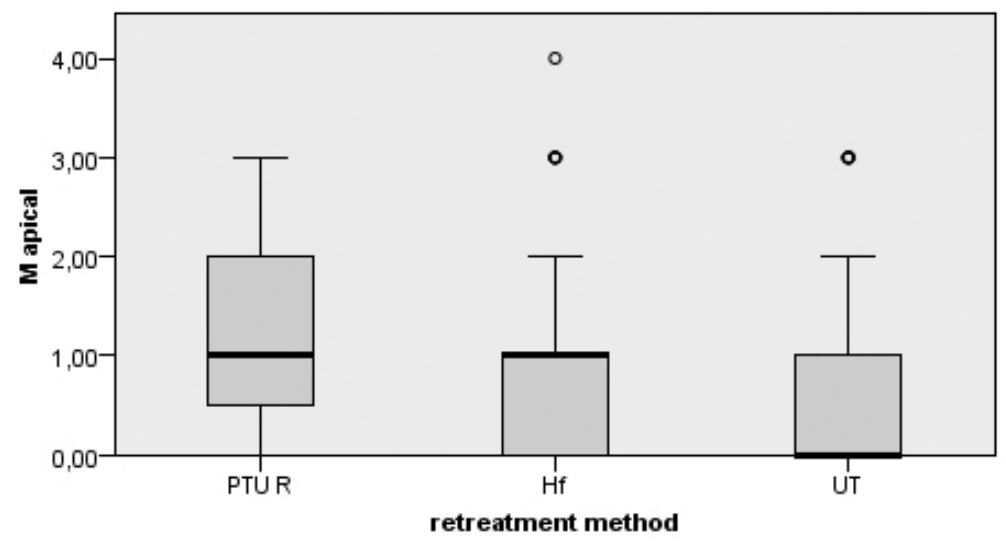

The ultrasonic tips presented best in the apical part. In $39.39 \%$ of the samples there was no residual material at all. For the NiTi machine and hand instruments the percent were 16.66 and 28.78 respectively. When central cone technique was used, best removal of root canal filling material was observed in the coronal and middle part with hand instruments. In the apical part the ultrasound tips performed better than the hand instrumentation (lowed median), although the difference was not statistically significant (table 3). The machine instruments presented significantly worse than the ultrasonic $(p=0.006)$. 
Table 3: Difference in the effectiveness of cleaning of teeth filled with central cone technique in the different parts of the root canal with different techniques.

\begin{tabular}{|l|l|l|l|l|}
\hline $\begin{array}{l}\text { Part of the root } \\
\text { canal }\end{array}$ & $p$ overall & $p$ machine/ hand & $\begin{array}{l}p \text { machine/ } \\
\text { ultrasonic tips }\end{array}$ & $\begin{array}{l}p \text { hand/ ultrasonic } \\
\text { tips }\end{array}$ \\
\hline Coronal & $<0.001$ & $<0.001$ & 0.001 & 0.517 \\
\hline Middle & 0.005 & 0.002 & 0.476 & 0.010 \\
\hline Apical & 0.023 & 0.088 & 0.006 & 0.390 \\
\hline
\end{tabular}

There was no statistically significant difference in the amount of the remaining root canal filling material in the coronal and middle third of the canal between the different techniques when lateral compaction technique was used. The ultrasonic tips performed best in the apical part, although the difference with the hand instrumentation was not statistically significant (table 4).

Table 4: Difference in the effectiveness of cleaning of teeth filled with lateral compaction technique in the different parts of the root canal

\begin{tabular}{|l|l|l|l|l|}
\hline $\begin{array}{l}\text { Part of the root } \\
\text { canal }\end{array}$ & $p$ overall & $p$ machine/ hand & $\begin{array}{l}p \text { machine/ } \\
\text { ultrasonic tips }\end{array}$ & $\begin{array}{l}p \text { hand/ ultrasonic } \\
\text { tips }\end{array}$ \\
\hline Coronal & .591 & .397 & .360 & .901 \\
\hline Middle & .893 & .875 & .758 & .642 \\
\hline Apical & .033 & .040 & .021 & .455 \\
\hline
\end{tabular}

When comparing the results achieved with the computed tomography it was established that it revealed less filling material than the control with the operating microscope. The correlation between the results achieved with the computed tomography and the microscope observation are presented on (table 5).

Table 5: Correlation between the results achieved with computed tomography and operating microscope

\begin{tabular}{|l|l|l|l|}
\hline & Coronal part & Middle part & Apical part \\
\hline Kendall's tau b & 0.347 & 0.177 & 0.255 \\
\hline Sig.(2-tailed) & 0.002 & 0.134 & 0.024 \\
\hline $\mathrm{N}$ & 66 & 66 & 66 \\
\hline
\end{tabular}




\section{Discussion}

Complete removal of all filling materials from the root canal during the retreatment is very important for the uncovering of the necrotic tissues and bacteria that might be responsible for the endodontic failure [Rôças 2004]. The results showed that a complete removal of the filling material, no matter of the filling technique or retreatment method couldn't be achieved. This corresponds with the results of some other authors [Ersev 2012, Uzunoglu 2015, Oltra 2016]. Worst cleaning as a whole was observed in the coronal part of the root canal. Uzunoglu et al and Oltra et al found the same $[16,20]$. This might be attributed to the root canal anatomy. The ultrasonic and hand instruments presented significantly better than the NiTi machine instruments. This does not correspond to some other studies [13, 14, Bramante 2010,]. Concerning the ultrasonic instruments this might be attributed to the vibrations of the tip that lead to de-bonding of the sealer on one side and the heat, generated by the friction of the tip, that leads to plasticization of the gutta-percha on the other [Rashad-Junior 2014]. Compared with the hand instruments, the machine NiTi rotary instruments does not fit that well to the root canal walls, especially in cases with oval shaped canals, which might be the explanation of the better results achieved with the hand instruments.

Best removal of filling material was achieved in the middle part or the root canal. This might be explained with the fact that in this region the anatomy is not that complex as in the apical region or at the level of the orifice, the walls are smooth and the sealer is easier to be removed. In the apical one-third the achieved results were closer to that from the coronal part, although a little bit better. This might again be attributed to the specific anatomy in this region and the difficult instrumentation. Worst results were achieved with the machine instruments. This could be explained with the fact that the tip of D3 file is \#20, while F2 (the file till which we have enlarged) file's tip is \#25. So the tip of D3 does not correspond exactly to the diameter of the canal and more remnants might be expected. That is why there are authors who does not recommend the separate use of machine rotary instruments and recommend their combining with hand instruments for ensuring better results [14]. This was the region where the biggest amount of residual gutta-percha ( $9 \%$ of the cases) was observed. A possible explanation of this fact might be that we have placed gutta-percha solvent only in the coronal part of the root, so in this region its plasticization and removal was harder.

Orange oil was used as a solvent in the presented study. Xylol and chloroform are classified as one of the strongest solvents of gutta-percha [23] but they also present the most undesirable effects to the periapical tissues and are considered potentially carcinogenic and neurotoxic [24,25]. According to some studies the effect of orange oil is statistically similar to that of chloroform [26] and xylol [27] although there are also studies with opposite results $[28,29]$. We have preferred it because it's accepted as safe, biocompatible and are non-carcinogenic [26].

The residual filling material after root canal retreatment was evaluated using several different techniques. One way was the longitudinal sectioning of the tooth, followed by observation under microscope and measured linearly [Imura 2000] or using evaluation scales [Barrato 2002, Sae Lim 2000]. The basic limitation this type of studies is that residual obturation material may be displaced and lost while splitting the roots. Other authors have used radiographic examination [Masiero 2005, Gergi 2007]. There are also studies where specimens were rendered transparent, photographs were made and the residual material was evaluated [Tasdemir 2008, Gu 2008]. The limitation of both type of studies is the two-dimensional information that radiographs and photographs give for a three-dimensional object. Computed tomography is a noninvasive method that allows observation of morphological features in detail [Bergmans 2001]. 


\section{Conclusions}

Complete removal of filling material was not achieved in any part of the root canal. Best removal of filling material was achieved in the middle part or the root canal and worse in the coronal. When central cone technique was used, best cleaning was observed with hand instruments in the coronal and middle part and with ultrasound in the apical part. There was no statistically significant difference in the coronal and middle third of the canal when lateral compaction technique was used, the ultrasound performed best in the apical part.

\section{References}

1. Eleman RF, Pretti I: Comparison of the success rate of endodontic treatment and implant treatment. ISNR Dent 2011 2011:640509.doi: 10.5402/2011/640509

2. Kojima K, Inamoto K, Nagamatsu K, Hara A, Nakata K, Morita I, Nakagaki H, Nakamura H: Success rate of endodontic treatment of teeth with vital and nonvital pulps. A meta-analysis. Oral Surg Oral Med Oral Pathol Oral Radiol Endod. 2004 97(1):95-9.

3. Ng YL, Mann V, Rahbaran S, Lewsey J, Gulabivala K: Outcome of primary root canal treatment: systematic review of the literature. Part two. Influence of clinical factors. Int Endodont J. 2008 41(1): 6-31

4. Tabassum S, Khan FR: Failure of endodontic treatment: The usual suspects. Eur J Dent. 2016 Jan-Mar;10(1):144-7; doi: 10.4103/1305-7456.175682

5. Tomson RM, Polycarpou N, Tomson PL: Contemporary obturation of the root canal system. Br Dent J. 2014 Mar;216(6):315-22. doi: 10.1038/sj.bdj.2014.205

6. Belli S, Ozcan E, Derinbay O, Unverdi Eldeniz A: A comparative evaluation of sealing ability of a new, self-etching dual curable sealer: Hybrid Root SEAL (MetaSEAL). Oral Surg, Oral Med, Oral Pathol, Oral Radiol and endodontology 2008

7. Tyagi S, Mishra P, Tyagi P: Evolution of root canal sealers: An insight story. Eur J Gen Dent 2013 2 199-218

8. Ginebra MP, Fernandez E, De Mayer EAP et al.: Setting reaction and hardening of an apatitic calcium phosphate cement. J Dent Res 1997 76(4) 905-912

9. Olivieira ACM, Tanomaru JMG, Faria-Junior N, Tanomaru-Filho M: Bacterial leakage in root canals filled with conventional and MTA-based sealers. Int Endod J 2011 44(4): 370-375

10. Camilleri J, Gandolfi MG, Siboni F, Prati C: Dynamic sealing ability of MTA root canal sealer. Int Endod J 2011 44(1): 9-20

11. Hess D, Solomon E, Spears R, He J: Retreatability of a bioceramic root canal sealing material. J Endodd 2011 37(11) 1547-1549

12. Al Haddad A, ZA Che Ab Aziz. Bioceramic-Based Root Canal Sealers: A Review. Int J Biomaterials 2016; 10p. doi: 10.1155/2016/9753210

13. Donnermeyer D, Bunne C, Schäfer E, Dammaschke T. Retreatability of three calcium silicatecontaining sealers and one epoxy resin-based root canal sealer with four different root canal instruments. Clin Oral Investig. 2017 Jun 22. doi: 10.1007/s00784-017-2156-5.

14. Siotia J, Acharya SR, Gupta SK: Efficacy of ProTaper retreatment system in root canals obturated with gutta-percha using two different sealers and guttaflow. Int J Dent 2011, doi:10.1155/2011/676128 
15. Zemener $\mathrm{O}$, Pameijer $\mathrm{CH}$, Banegas G. Retreatment efficacy of hand versus automated instrumentation in oval-shaped root canals: an ex vivo study. Int Endod J 2006 39(7) 521-526

16. Oltra E, Cox TC, LaCourse MR, Johnson JD, Paranjpe A: Retreatability of two endodontic sealers, EndoSequence BC Sealer and AH Plus: a microcomputed tomographic comparison. Rest Dent Endod 2017 42(1):19-26. doi: 10.5395/rde.2017.42.1.19.

17. Hammad M, Qualtrough A, Silikas N: Three-dimentional evaluation of effectiveness of hand and rotary instrumentationfor retreatment of canals filled with different materials. J Endodd 2008 34(11): 1370-1373

18. Rôças IN, Jung IY, Lee CY, Siqueira JF Jr. Polymerase chain reaction identification of microorganisms in previously root-filled teeth in a South Korean population.J Endod. 2004 30(7): 504-8.

19. Ersev H, B Yilmaz, ME Dinçol, R Dağlaroğlu: The efficacy of ProTaper Universal rotary retreatment instrumentation to remove single gutta-percha cones cemented with several endodontic sealers. Int Endod J 201245 756-762 doi:10.1111/j.1365-2591.2012.02032.x

20. Uzunoglu E., Z. Yilmaz, D. Sungur, E. Altundasar. Retreatability of root canals obturated using Gutta-Percha with bioceramic, MTA and resin-Based Sealers. Iranian Endodontic Journal, 2015, 10(2): 93-98

21. Bramante CM, NS Fidelis, TS Assumpção, N Bernardineli, RB Garcia, AS Bramante, IG de Moraes. Heat release, time required and cleaning ability of Mtwo R and ProTaper Universal retreatment systems in the removal of filling material. J Endod 2010 36(11): 1870-1873

22. Rached-Junior F., M. Sousa-Neto, J. Bruniera, M. Duarte, Y. Silva-Sousa. Confocal microscopy assessment of filling material remaining on root canal walls after retreatment. International Endodontic Journal, 2014 47:264-270

23. Görduysus MÖ, Tasman F, Tuncer S, Etikan I. Solubilizing efficiency of different gutta-percha solvents: a comparative study. J Nihon Univ Sch Dent 1997 39:133-135.

24. Wourms DJ, Campbell AD, Hicks ML, Pelleu GB Jr. Alternative solvents to chloroform for guttapercha removal. J Endod. 1990 16(5): 224-226.

25. Barbosa SV, Burkard DH, Spangberg LS. Cytotoxic effects of gutta-percha solvents. J Endod. 1994 20(1):6-8.

26. Magalhães BS, JE Johann, RG Lund, J Martos, FAB Del Pino: Dissolving efficacy of some organic solvents on gutta-percha Braz. oral res. 200721 (4): 303-7.

27. Oyama KON, EL Siqueira' M dos Santos: In vitro study of effect of solvent on root canal retreatment. Braz Dent J 2002 13 (3): 208-211; http://dx.doi.org/10.1590/S010364402002000300014

28. Martos J, Bassotto AP, González-Rodríguez MP, Ferrer-Luque CM. Dissolving efficacy of eucalyptus and orange oil, xylol and chloroform solvents on different root canal sealers. Int Endod J. 2011 44(11): 1024-1028. doi: 10.1111/j.1365-2591.2011.01912.x.

29. Pécora JD, Spanó JC, Barbin EL. Braz Dent J. 1993;4(1):43-7.In vitro study on the softening of gutta-percha cones in endodontic retreatment.

30. Imura N, Kato AS, Hata GI, Uemura M, Toda T, Weine F. A comparison of the relative efficacies of four hand and rotary instrumentation technique during endodontic retreatment. Int Endod J 2000 33:361-6

31. Baratto Filho F, Ferreira EL, Fariniuk LF. Efficiency of the 0.04 taper ProFile during the retreatment of gutta-percha-filled root canals. Int Endod J 2002 35:651-4.

32. Sae-Lim V, Rajamanickam I, Lim BK, Lee HL. Effectiveness of ProFile. 04 taper rotaryinstruments in endodontic retreatment. J Endod 200026 100-104 
33. Masiero AV, Barletta, FB. Effectiveness of different techniques for removing gutta-percha during retreatment. Int Endod J 2005 38:2-7

34. Gergi R, Sabbagh C. Effectiveness of two nickel-titanium rotary instruments and a hand file for removing of gutta-percha in severely curved root canals during retreatment: an ex vivo study. Int Endod J 2007 40:532-537

35. Tasdemir T, Er K, Yildirim T, Celik D. Efficacy of three rotary NiTi instruments in removing guttapercha from root canals. Int Endod J 2008 41:191-196.

36. Gu LS, Ling JQ, Wei X, Huang XY. Efficacy of ProTaper Universal Rotary retreatment system for gutta-percha removal from root canals. Int Endod J 2008 41:288-295.

37. Bergmans L, Van Cleynenbreugel J, Wevers M, Lambrechts P. A methodology for quantitative evaluation of root canal instrumentation using microcomputed tomography. Int Endod J 2001 34:390-8.

\section{Corresponding author:}

Mirela Marinova-Takorova

Department of Conservative Dentistry

Faculty of Dental Medicine

Medical University

Sofia, Bulgaria

email: marinova.takorova@gmail.com 